JPCW MS 105

Title: Measuring Client Satisfaction with Child Welfare Services

Author names:

Dr Clare Tilbury, BSocWk, MPhil, PhD

Dr Jennifer Osmond, BSocWk (Hons), PhD

Ms Meegan Crawford, BSocWk

Authors' affiliation:

School of Human Services, Griffith University, Australia

Address:

c/- Clare Tilbury

School of Human Services

Griffith University, Logan campus

University Drive

MEADOWBROOK Q 4131 AUSTRALIA

Email: c.tilbury@griffith.edu.au

Telephone: + 61 (0)7 33821406

Key words: Child welfare, performance measurement, client satisfaction 


\title{
Measuring Client Satisfaction with Child Welfare Services
}

\begin{abstract}
This article examines the role of client satisfaction indicators in child welfare agency performance measurement. It examines both research and performance measurement efforts to understand client perspectives on child protection and out-of-home care services. It highlights the value of obtaining data from clients about their experience of the service delivered by the agency and its impact on their lives. Conceptual, methodological and ethical issues in implementing routine, standardized data collection on client satisfaction are discussed. Measuring client satisfaction within a suite of performance indicators is an example of how practitioners and managers can use one of the tools of managerialism in the interests of clients and good practice.
\end{abstract}




\section{Measuring client satisfaction with child welfare services}

Over the last two decades, changes in the political economy of welfare in most developed countries have resulted in new modes of funding, managing and delivering human services. The managerial orthodoxy has had a significant impact: (a) a focus on quantifiable outputs and outcomes; (b) increased competition through tenders and contracts for service delivery; and (c) the introduction of business management principles and new approaches to accountability (Harris \& MacDonald, 2000). Standard-setting, performance measurement and evaluation are key regulatory mechanisms introduced to manage expenditure and provide accountability. Such mechanisms offer the possibility of clarifying goals and achievements, a focus on quality and effectiveness, and an empirical basis for debate and action. However, if separated from substantive organizational quality improvement processes, they can divert attention from the real markers of quality practice, thereby shifting the focus of professionals from client interests to organizational demands (Harris, 1998). The regulatory mechanisms come to be seen as administrative or managerial rather than as professional activities concerned with quality and accountability to clients. This has largely been the fate of performance measurement, which involves the collection and analysis of administrative data to report on the effectiveness and efficiency of services.

There have been a number of problems identified with performance measurement in child welfare, such as: (a) goal displacement whereby achieving targets supersedes meeting individual client needs; (b) the weak links between research on what constitutes good performance in child welfare and the performance indicators established by government; (c) a tendency to rely on cross sectional data and what is easily counted rather than what should be counted; and (d) failure to adjust for social and demographic factors that impact upon performance data (Courtney, Needell \& Wulczyn, 2004). The views of children and parents 
about service effectiveness have rarely informed performance measurement in child welfare. Despite these limitations, performance measurement is widely used. If aligned with research and policy, it is a useful tool for managing human services. Just as practice should be informed by sound research, so should policy - and performance measurement is a policy tool. Establishing performance indicators potentially influences how social problems such as child maltreatment are defined, where resources are placed, what service types are funded, and how outcomes for clients are conceptualized (Tilbury, 2004). It is argued here that performance measurement regimes - the indicators themselves plus the performance improvement strategies that data inform - should be based as much as possible on the evidence base about how to achieve quality and good outcomes.

This article relates to a specific area of focus for performance measurement measuring client satisfaction with services. In the managerial approach, clients of human services are recast as customers or consumers. There are questions about whether these private sector concepts are appropriate to social welfare services, especially for statutory agencies whose clients may not be voluntary (Gleeson, 1999; Vardon, 1997). Consumers of public services are also citizens, implying rights to equity, representation and participation (Pollitt, 1998). But within social work research and practice, ideas about client participation, empowerment and consumer rights have been around for decades and are compatible with assessing client experiences of service delivery. The rhetoric of empowering the citizen as consumer, customer or service user has been renewed since the 1990s. It is terminology used across the political spectrum in human services: either in rejecting the perceived depersonalization of welfare bureaucracies, or in promoting the idea of welfare as a market (Harris \& MacDonald, 2000).

The article reviews selected international literature on measuring client satisfaction, particularly in the child welfare field. It examines both research and performance 
measurement efforts to understand client perspectives on child protection and out-of-home care services. It then discusses conceptual, methodological and ethical issues in routinely measuring client satisfaction, and how to maximize its value.

\section{Impetus for Measuring Client Satisfaction in Human Services}

Obtaining client satisfaction data is "a systematic attempt by agencies to get reliable and valid data from clients regarding their perceptions of both how services were given, and the benefits they derived” (Weissman, 1988, p.206). Here, both process (how services are delivered) and outcome (benefits derived) dimensions of the client experience are identified. The argument is that the recipients of services ought to have a voice in indicating whether services met their expectations and needs. This accords with many approaches to evaluation that encourage the inclusion of consumer perspectives to promote accountability and a pluralistic account of effectiveness (Everitt \& Hardiker, 1996). Weissman (1988) argues the desire for obtaining client feedback was spurred by the consumer movement that emerged in the 1970s. Radical and feminist approaches to practice also endorsed empowering forms of practice and consumer-oriented perspectives (Dominelli, 1996). There are social work references from the 1970s that urge the inclusion of the client perspective in agency evaluation and program development (O'Neal, 1999; Weissman, 1988). This includes the landmark English study, The Client Speaks - Working Class Impressions of Casework, which found wide disparities between the service clients expected to receive from social workers, and what they actually received, with consequences for their satisfaction levels (Mayer \& Timms, 1970).

The service user movement has gained increasing prominence in social welfare policy in the last decade. This has occurred alongside a post-modern reappraisal of the nature of knowledge that recognizes the importance of client theorizing and knowledge. Understanding the lived experiences of clients is seen as essential to informing professional reflection and 
action (Beresford \& Croft, 2001). In addition, as understandings of evidence-based practice for social services have evolved, service user knowledge has been recognized as a vital part of the equation. Clients actively participate in service provision as they use and reflect upon interventions designed to assist them (Johnson \& Austin, 2006). That is, evidence-based practitioners must integrate the best available knowledge about what works with individual client values, capacities and expectations (what works for whom, in what circumstances?).

At a more instrumental level, client satisfaction data can contribute to better practice and service delivery. Measuring client satisfaction is a mechanism to obtain insight into how clients understand the child welfare process and what they interpret from events or decisions (Harris, Poertner \& Joe, 2000). Such data can assist practitioners in their efforts to engage with clients, and inform the design of service delivery improvement strategies. It is also argued that the process of being asked for their opinion is empowering, as the agency sends a message about the importance of listening to clients (Baker, 2007).

The term client satisfaction is contested. When the client is not using a service on a voluntary basis, such as clients of child welfare agencies, corrective services, court-mandated alcohol and drug rehabilitation services, then the client may not agree that they need the service that the agency is providing to them, and may not see any benefit accruing to them (Gain \& Young, 1998). Or, the service is nominally voluntary but essential (for example, housing or income support) and clients do not really have a choice about not using the service. Clients of welfare services are not like customers or consumers in the sense that they exchange money for services so they can choose what services to use and can shop around. Designating the recipients of human services as clients or consumers is intended to convey a more active engagement than recipient status - that clients are entitled to respectful, individual attention even if they do not pay for services (Vardon, 1997). Agencies can measure whether the client is treated with respect, is listened to, understands decisions that 
are made, and understands rights and so on. For these reasons, terms such as client feedback or client perspective may be preferred to client satisfaction.

While client or consumer perspectives may be widely championed, there are concerns about how client satisfaction data may be used. Notions of good performance may be narrowly defined so as to stifle debate about resource deficits (Beresford \& Croft, 2001). For example, client dissatisfaction with services may reflect poorly-funded services rather than poor quality services, or clients may find a service objectionable in the short-term that they come to appreciate in the longer-term. Yet despite the political, conceptual, methodological and ethical problems involved in doing so, there is a general consensus in the literature that obtaining client satisfaction data is ‘a good thing’ (Fuller \& Petch, 1995). All clients, including those who are children and those with disabilities or mental illnesses, are regarded as having the capacity to report on their own circumstances and assess their own needs (O'Neal, 1999; Wilson \& Conroy, 1999). Determining levels of client satisfaction is seen as important for seeking out and valuing client opinions, especially those historically devalued or silenced. Asking clients their views reinforces their status as thinking people, capable of insight (Mayer \& Timms, 1970).

\section{Measuring Client Satisfaction in Child Welfare Services}

Client satisfaction may be seen as an important measure of quality in agency performance measurement and evaluation, but there have been few systematic attempts to obtain clients' views about child protection and out-of-home care services. The importance of obtaining client perspectives has been recognized in research to some degree. A recent review of research on out-of-home care located twenty-two studies that included children's perspectives, dating back to Fanshel and Shinn’s 1978 study (cited in Fox \& Berrick, 2007). Most of these studies used interview methods of data collection. On the whole, children have indicated that they felt safer in out-of-home care, expressed the importance to them of 
maintaining relationships with family of origin members while building new relationships in care, and want to be properly included in decision-making (Fox \& Berrick, 2007; Delfabbro, Barber \& Bentham, 2002).

Research has mainly concentrated on children in out-of-home care. There is a related body of literature exploring the perspectives of youth previously in care on their transition to independent living (Baker, 2007). There is less research on how children or parents understand the initial stages of becoming involved in the child welfare system. The overview of British research studies on child protection, Child Protection: Messages from Research contained findings from several studies that examined the views of parents about their involvement in the child protection process. This research synthesis highlighted the distress experienced by families and the benefits of working in partnership so parents understand the goals and rationale for intervention. It revealed that disagreement with parents hindered the capacity of professionals to achieve desired outcomes, and that cooperation with intervention plans was enhanced if parents felt they were "heard” (Department of Health, 1995).

However, research that involves the views of children and parents is different from performance measurement efforts, through which child welfare agencies themselves seek client feedback to aid organizational improvement, and then monitor satisfaction levels over time. The main method for obtaining client satisfaction data for performance measurement is through conducting surveys. Such client surveys are not common practice in child welfare, and if they are conducted, are often not reported in the literature and are not ongoing (Baker, 2007; Gain \& Young, 1998).

In contrast to the general picture, a series of four annual surveys of the satisfaction of children in out-of-home care, and their parents, was conducted in Illinois in the 1990s (Wilson \& Conroy, 1999). The results of the parent surveys are not reported in the literature. The surveys of children confirmed their ability to report on their own circumstances and 
assess their own needs. The survey instrument contained 49 quantitative questions and seven open-ended qualitative questions, administered in face-to-face interviews. Samples of 250 to 300 children aged between five years and 18 years were surveyed. Most children reported feeling "loved" and "safe”. Children in family foster care were more satisfied than those in group care, and children were dissatisfied with their input in decision-making by courts and their caseworkers. In Kansas, the parents of children in foster care $(n=184)$ were surveyed via a telephone survey, using a standardized instrument with 34 items (including four openended questions) to measure satisfaction. The domains of worker competency, agency quality, outcomes, empowerment, strengths and cultural competency were explored. The survey revealed a wide range of satisfaction levels, and confirmed that good professional practice (respect for individuals, cultural awareness, clear and open communication, asking about needs and services) predicted parent satisfaction (Kapp \& Vela, 2004).

While the British government places significant policy emphasis on user participation in social services, there is no national client satisfaction indicator for children's services. Nevertheless, the government has conducted surveys of a wide range of social service users at the national level. In 2004-05, a large postal survey of children aged between ten years and 17 years receiving social services, received responses from 22,000 children. However, there were problems with the administration of the survey which undermined data quality. The response rates were very low in some local areas, and there were concerns about the reliability of the survey instrument (which comprised eight structured response questions about quality and choice of services (Department for Education and Skills, 2005). In a small study, an English local authority commissioned research to investigate the views of children in their care. This involved unstructured interviews with a non-representative sample of fifteen children aged between ten years and 17 years. The young people expressed concern about multiple workers and lack of confidentiality, with older children especially feeling they 
did not have enough say in their lives. Differences were noted between how children defined good quality services (particularly a trustworthy relationship with a caseworker) and the markers of quality in performance indicators (Munro, 2001).

All states in Australia have agreed that client satisfaction should be listed as a performance indicator for child protection and out-of-home care services, but comparable means to measure this aspect of performance across jurisdictions has not yet been developed (Steering Committee for the Review of Commonwealth/State Service Provision, 2007). Client satisfaction surveys have been conducted in two states in Australia. In Victoria, the Department of Human Services commissioned a client survey involving 457 young people over the age of 11 years, and 472 family members. The telephone survey comprised 44 questions including nine open-ended questions about experiences of the services received. There were versions for both children and parents (Shane Thomas and Associates, 2002; Steering Committee for the Review of Commonwealth/State Service Provision, 2003). In Queensland, the Department of Families commissioned a telephone survey of young people over 12 years $(n=216)$, their families $(n=150)$ and foster carers $(n=477)$ for the purpose of improving service delivery and reporting on performance (Steering Committee for the Review of Commonwealth/State Service Provision, 2003). These surveys, like many others conducted, have not been incorporated into routine performance measurement and little information is available about steps taken to improve performance based on their findings. This limits their value, as client feedback surveys need to be conducted periodically (at least annually) in order for agencies to use the results to improve their services.

\section{Discussion}

The efforts to date to obtain child and family feedback on child welfare services have identified a number of conceptual, methodological and ethical issues to consider: 
Defining the client. The first conceptual issue relates to defining the client. First, there are multiple client views, because clients are not a homogeneous group (Fuller \& Petch, 1995). For example, clients from minority ethnic groups and indigenous clients who are over-represented in care systems may have particular expectations and concerns. For most child welfare agencies, there are two distinct client groups - children and parents - who may have conflicting interests. Children may judge intervention to be effective if they are no longer at risk of harm, but their parents may resent the intrusion into family life. Moreover, clients are not just those presently receiving services - former clients and potential clients (who need the service but may not get access to it) should also be considered.

Obtaining informed consent. There are ethical issues to be addressed in obtaining data from children and parents who are clients of child welfare agencies. The age and status of clients, their relatively powerless position, and their reliance on the agency may affect their capacity to truly give informed consent (Alderson, 1995; Gain \& Young, 1998).

Compounding this, parents may have learning disabilities or other problems that can impair their understanding of consent. Clients have to understand that even though participation in a survey may help other clients by improving the service overall, they may not be helped personally.

There are specific consent issues in relation to children in out-of-home care. Should biological parents be informed about their children being surveyed, even if the child is in the guardianship of the State? Consent may be given by the legal guardian (via the statutory worker or agency) but at what age should the child have the right to consent on her or his own behalf? And how do children understand their right not to participate (Berrick, Frasch \& Fox, 2000)? There are no correct answers to these questions; they must be considered in the context of the purpose of the study. Wilson and Conroy (1999) managed this ethical risk by obtaining the approval of the guardian (the government agency) plus oral consent from 
children. Because children are less powerful than the adult researcher, Munro (2001) argued that an unstructured interview was more ethical because it maximized children's control over the research process, given they only talked about those topics that mattered to them. This has implications for the capacity to obtain information from large samples.

Timing and methods of data collection. Measuring client satisfaction is particularly important when service delivery involves prolonged personal contact. If outcome measures are distal, proximal indicators such as how you are treated become all the more significant. Obviously, the timing of a survey of client views should suit the client, not the agency. Seeking feedback during a crisis is not likely to be appreciated and may exacerbate a fear of reprisals (Weissman, 1988), however, clients’ opinions should generally be sought during the period of service delivery. There are problems with only measuring at the conclusion of service delivery due to the non-participation of clients who drop out or disengage part-way through because they did not feel their needs were sufficiently understood or effectively responded to. For human services, there is often no clear-cut end point of intervention and no observable improvement may be expected. That is, stabilizing or maintaining a situation, or preventing deterioration, may be the goal (Nocon \& Qureshi, 1996). Agencies also need to be concerned about intrusiveness, especially if contacting clients after they have left the agency.

Methods of data collection have to account for people who may be transient, have low literacy skills, mental health problems, drug and alcohol problems, or no telephone. While telephone and interview methods have both been used successfully, Kapp \& Vela (2004) reported difficulties contacting clients because telephone numbers provided were inaccurate or out-of-date. Consequently low return rates must be considered a reliability problem, because non-returns are open to being interpreted as dissatisfaction and unrepresentative samples limit generalisability (Gain \& Young, 1998; O'Neal, 1999; Gilbertson \& Barber, 2002). In addition to the ethical issues raised about quantitative measures (above), it is 
suggested that a mix of quantitative and qualitative methods may optimize the quality and depth of data obtained (Berrick et al., 2000). However this poses difficulties for routine performance measurement, in terms of capacity to reach larger sample sizes and to administer from year to year. Face-to-face interviews may also be problematic compared to confidential and anonymous surveys.

Validity and reliability. There are validity and reliability problems related to client self-assessments. Clients might fear providing an honest assessment of a service because of the perceived power of the agency to make decisions that affect their lives or to withdraw services if negative feedback is given (O’Neal, 1999; Weissman, 1988). Clients may have very low expectations of a service, and if these expectations are met or exceeded, an inflated satisfaction assessment might result: the contrast effect. Clients may be suspicious of agencies, not wanting to make anything formal or written down. If they feel helpless or dependent they may want to please, whereas other clients may be cynical about the possibilities for change (Weissman, 1988). Such issues highlight the limitations of a single, overall satisfaction score.

There are obvious advantages to using a consistent and standardized approach to measuring client satisfaction. Two standardized instruments have been developed to measure parent satisfaction which have psychometric properties reported; the Parents with Children in Foster Care Satisfaction Scale (Harris et al., 2000); and the Parent Satisfaction with Foster Care Services Scale (Kapp \& Vela, 2004). An instrument measuring children’s satisfaction (Wilson \& Conroy, 1999) and an instrument adaptable for both parents and children (Shane Thomas and Associates, 2002) have also been tested. However, their validity and reliability characteristics were not reported. Harris et al. (2000) argue that validity and reliability are enhanced if clients are involved in the development of the data collection instrument, because they can help identify the elements of the service transactions that are important. This was the 
approach taken in many of the surveys discussed here. It is essential that questions reflect the issues of importance to users, because as Mayer and Timms (1970) showed, levels of satisfaction are dependent upon the expectations that clients bring to the service transaction.

The notion of client satisfaction is inherently subjective. One client's perception of the empathy of workers will differ from another's. Moreover, does the client's feedback really indicate whether the service has had a positive or negative impact on their life? Nocon and Qureshi (1996) argue that satisfaction is not correlated with beneficial outcomes. There is a difference between the provision of a quality service and long-term improvements in a client's situation. Identifiable changes in a client's situation or behavior may be more useful in measuring outcomes than the client's own assessment of the process. This goes to the question of whether client satisfaction should be used as an indicator of client outcomes or service quality (Gain \& Young, 1998). The client must be asked about the extent to which the service has made a difference to their life, in addition to satisfaction with services. Still, such data only indicates the degree to which services have fulfilled a client's subjective needs, expectations or wishes. This is not the same as objective data about a client's status for example a client might feel a service has helped them to improve their parenting even though they are still exhibiting considerable skill deficits. Clearly client satisfaction is only one indicator of the quality of services, which must be balanced with other effectiveness and outcome measures (O'Neal, 1999).

Sensitivity of instruments. Research suggests that regardless of the product being evaluated, crude inquiries of the level of satisfaction will generate positive responses in the order of 80 per cent, so methodologies must be sufficiently sensitive to counteract the tendency towards broad statements of approval (Fuller \& Petch, 1995). A review of consumer satisfaction studies in the mental health field confirms most surveys reported satisfaction ratings of 80 per cent or greater, and O'Neal (1999) contends that the fear of 
losing a service, the tendency to acquiesce to authority, and the lack of standards of comparison are factors that lead to most clients expressing positive opinions about services. A positive response might mean only that the service is better than nothing. Broad statements of satisfaction can also mask specific and serious concerns about particular issues. Instruments must be specific, and the reasons for client satisfaction or dissatisfaction identified, so the link to quality improvement can be made (Harris et al., 2000). It is further argued that clients should assess detailed elements of the service transaction, rather than satisfaction in global terms, which does not yield information about what aspects of services need to be improved (Harris et al., 2000; Unrau, 2001).

Accepting negative feedback. Client empowerment can mean limitations on agency autonomy, and agencies need to be prepared for negative feedback. Using client feedback to inform policy and practice development is not always taken seriously. For example, agency administrators and staff may be fearful of negative assessments of their practice or programs and may resist change. They may judge client surveys to be less about benefits to clients than about organizational goals of self-justification (Weissman,1988; Gleeson, 1999). Mayer and Timms (1970) suggested that social workers may undervalue client opinion, casting clients as unreliable, rather than as thinking persons capable of insight. This may be particularly the case for child welfare clients who are parents, and who are given an involuntary or noncompliant label. Such attitudes engender a climate of reluctance to enter into partnerships and to listen rather than blame. In fact, it has been a hallmark of some constructions of professionalism that the worker knows best, with client grievances interpreted as resistance or a challenge to professional competence. Measuring client satisfaction as a routine part of performance measurement, and using the feedback to make improvements to agency performance, can send a message to both staff and clients that client perspectives are legitimate, and to be taken seriously. 
Grievances and complaints may also be inevitable and not easily resolvable, given that many child welfare clients are teenagers seeking more independence. For example, some children in residential care in a study by Delfabbro et al. (2002) wanted to be able to smoke and stay out later at night - the types of dissatisfactions experienced by many young people in making the transition to adulthood. But such criticisms should not be dismissed out-ofhand, for even in risk-averse child welfare systems, young people must have the opportunity to test boundaries and incrementally exercise more freedom and self-discipline (Munro, 2001).

\section{Conclusion}

In child welfare as in other fields of social work practice, measuring client satisfaction is a complex task to be approached carefully. But there is a strong rationale for including feedback from children and parents within a set of performance indicators and in agency evaluations. Standardizing instruments and processes for obtaining child and family feedback, and incorporating client feedback into performance improvement strategies, can elevate the client voice in a manner not achievable through informal or ad hoc mechanisms. This article has identified a range of practice issues and ethical challenges - obtaining valid consent, appropriate timing, reliable and valid data collection methods - but these can be managed through careful consideration of the purpose and scope of the data collection. There are many reasons to take a systematic approach to understanding how children and families experience child welfare services. Measuring client satisfaction appeals to both professional principles of listening to and engaging with clients, as well as to managerial ideas of quality improvement and outcome measurement. The collection and use of performance data is essential to good planning and program implementation. Actively using client feedback is also integral to evidence-based policy and practice, providing an empirical basis for action. The impetus for measuring client satisfaction also reflects a client-centred approach in which 
Measuring client satisfaction - 16

there is a commitment to good practice, openness to change, and an appreciation for accountability to clients. 


\section{REFERENCES}

Alderson, P. (1995). Listening to children: children and social research ethics. London: Barnado’s.

Baker, A. J. L. (2007). Client feedback in child welfare programs: current trends and future directions. Children and Youth Services Review, 29, 1189-1200.

Berrick, J.D., Frasch, K., \& Fox, A. (2000). Assessing children’s experiences of out-of-home care: methodological challenges and opportunities. Social Work Research, 24, 119128.

Beresford, P. \& Croft, S. (2001). Service users' knowledges and the social construction of social work. Journal of Social Work, 1, 295-316.

Courtney, M.E., Needell, B., \& Wulczyn, F. (2004). Unintended consequences of the push for accountability: the case of national child welfare performance standards. Children and Youth Services Review, 26, 1141-1154.

Delfabbro, P.H., Barber, J.G., \& Bentham, Y. (2002). Children’s satisfaction with out-ofhome care in South Australia, Journal of Adolescence, 25, 523-533.

Department for Education and Skills (2005). Survey of children and young people receiving personal social services in England aged 10-17, 2004-05. Retrieved 23 November 2009 from http://www.dcsf.gov.uk/rsgateway/DB/SFR/s000622/index.shtml.

Department of Health (1995). Child Protection: Messages from Research. London: HMSO.

Dominelli, L. (1996). Deprofessionalising Social Work: anti-oppressive practice, competencies and postmodernism. British Journal of Social Work, 26, 153-175.

Everitt, A. \& Hardiker, P. (1996). Evaluating for Good Practice. London: Macmillan.

Fox, A. \& Berrick, J.D. (2007). A response to no-one ever asked us: a review of children’s experiences in out-of-home care. Child and Adolescent Social Work Journal, 24, 2351. 
Fuller, R. \& Petch, A. (1995). Practitioner research: the reflexive social worker. Buckingham UK: Open University Press, 1995

Gain, L. \& Young, L. (1998). Outcome measurement in child protection: International literature review and critical analysis of child protection and alternative placement outcome measures. Melbourne: Steering Committee for the Review of Commonwealth/State Service Provision.

Gilbertson, R. \& Barber, J. (2002). Obstacles to involving children and young people in foster care research. Child and Family Social Work, 7, 253-258.

Gleeson, J. (1999). Does the notion of customer satisfaction apply to child protection? Melbourne: Child Protection and Juvenile Justice Branch, Department of Human Services.

Harris, G., Poertner, J. \& Joe, S. (2000). The parents with children in foster care satisfaction scale. Administration in Social Work, 24, 15-27.

Harris, J. (1998). Scientific management, bureau-professionalism, new managerialism: the labour process of state social work. British Journal of Social Work, 28, 839-862.

Harris, J. \& MacDonald, C. (2000). Post-Fordism, the Welfare State and the Personal Social Services: A Comparison of Australia and Britain. British Journal of Social Work, 30, $51-70$.

Johnson, M. \& Austin M.J. (2006). Evidence-based practice in the social services: implications for organizational change. Administration in Social Work, 30, 75-104.

Kapp, S.A. \& Vela, R.H. (2004). The unheard client: Assessing the satisfaction of parents of children in foster care. Child and Family Social Work, 9, 197-206.

Mayer, J.E. \& Timms, N. (1970). The Client Speaks: working class impressions of casework. London: Routledge and Kegan Paul. 
Munro, E. (2001). Empowering looked-after children. Child and Family Social Work, 6, 129137.

Nocon, A. \& Qureshi, H. (1996). Outcomes of Community Care for Users and Carers. Buckingham UK: Open University Press.

O'Neal, P. D. (1999). Methodological problems associated with measuring consumer satisfaction in the mental health field. Australian Social Work, 52(3), 9-15.

Pollitt, C. (1998). Bringing consumers into performance measurement: concepts, consequences and constraints. Policy and Politics, 16, 77-87.

Shane Thomas and Associates (2002). Child Protection Client and Family Survey: Final Report 2002. Melbourne: Victorian Department of Human Services.

Steering Committee for the Review of Commonwealth/State Service Provision (2003). Report on Government Services 2003. Canberra: AusInfo.

Steering Committee for the Review of Commonwealth/State Service Provision (2007). Report on Government Services 2007. Canberra: AusInfo.

Tilbury, C. (2004). The influence of performance measurement on child welfare policy and practice. British Journal of Social Work, 34, 225-241.

Unrau, Y.A. (2001). Using client exit interviews to illuminate outcomes in program logic models: a case example. Evaluation and Program Planning, 24, 353-361.

Vardon, S. (1997). Are prisoners clients? Australian Journal of Public Administration, 56, 127-129.

Weissman, H. H. (1988). Planning for client feedback: content and context. Administration in Social Work, 11, 205-220.

Wilson, L. \& Conroy, J. (1999). Satisfaction of children in out-of-home care. Child Welfare, 78, 53-60. 